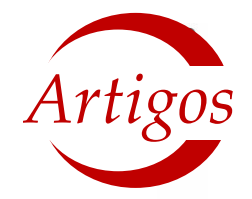

\title{
O cangaço e a literatura popular em versos: \\ a tradição na pós-modernidade
}

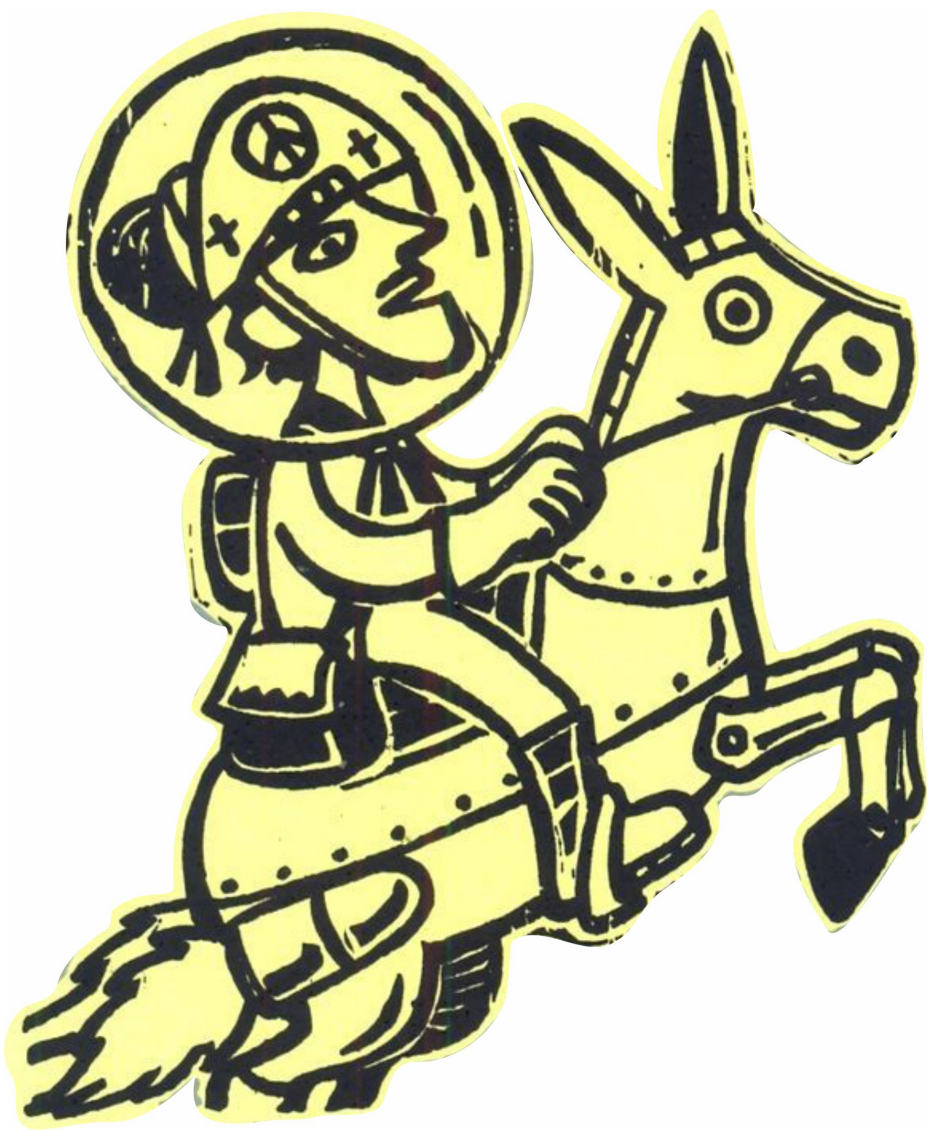

Capa do folheto $O$ cangaceiro do futuro e o jumento espacial, de Klévisson Vianna, 2008, fotografia (detalhe)

\section{Antônio Fernando de Araújo Sá}

Doutor em História pela Universidade Federal de Brasília (UnB). Professor do Departamento de História e do Programa de Pós-graduação em História da Universidade Federal de Sergipe (UFS). Autor, entre outros livros, de Entre sertões e representações: ensaios e estudos. São Paulo: Liber Ars, 2020. afsa@ufs.br 


\section{O cangaço e a literatura popular em versos: a tradição na pós- modernidade $^{1}$}

Cangaço and popular literature in verses: post-modernity tradition

\section{Antônio Fernando de Araújo Sá}

\section{RESUMO}

Ao analisar as representações do cangaço na literatura de folhetos, este artigo lança-se ao desafio de estabelecer um diálogo entre tradição e pósmodernidade, com o objetivo de romper com certa leitura arcaica ou quase medieval dessa produção literária. Como arena de consentimento e resistência, os folhetos foram forjados em consonância com determinada ideia essencialista de cultura popular, moldada no final do século XIX e primeira metade do século $X X$, formadora de um imaginário-base, reinventado na segunda metade do século $X X$ e início do XXI. Ao contrário daquela leitura arcaizante, abordamos a capacidade de renovação e permanente absorção de narrativas, de linguagens, de imaginários, especialmente com relação à cultura de massa e das tecnologias digitais, reveladora dos processos de resistência, mas também de conformismo, das culturas populares no Brasil.

PALAVRAS-CHAVE: literatura popular em versos; cangaço; representação.

\section{ABSTRACT}

$B y$ analyzing the representations of cangaço in the literature of leaflets, this article takes on the challenge of establishing a dialogue between tradition and postmodernity, with the aim of breaking with a certain primitive or almost medieval reading of this literary production. As an arena of consent and resistance, the leaflets were forged in line with a certain essentialist idea of popular culture, shaped in the late 19th and first half of the 20th century, forming an base imaginary, reinvented in the second half of the 20 th century and beginning of the 21st. Contrary to that primitive reading, we approached the capacity for renewal and permanent absorption of narratives, languages, imaginary, especially in relation to mass culture and digital technologies, revealing the processes of resistance, but also of conformism, of popular cultures in Brazil.

KEYWORDS: popular literature in verses; camgaço; representation.

\footnotetext{
${ }^{1}$ Texto revisto e ampliado de intervenção na mesa-redonda As pesquisas e o registro da cultura popular, do XLIV Simpósio do Encontro Cultural de Laranjeiras (10-12 jan. 2019), com participação dos pesquisadores Eliene Benício (UFBA) e Gutemberg Costa (IHGRN). Agradeço a gentileza do convite por parte da Secretaria de Estado da Cultura de Sergipe.
} 
Para refletirmos sobre a cultura popular em seu diálogo, nem sempre cordial, com a contemporaneidade, optamos por analisar as representações do cangaço na literatura popular em versos, tomando-a como expressão lírica dos poetas populares sobre a história do Brasil. Em meio aos labirintos da imaginação e da inventividade dessa produção literária, lançamo-nos ao desafio de estabelecer um diálogo entre tradição e pós-modernidade, na busca por romper com certa leitura arcaica ou quase medieval da literatura de cordel, inserindo-a na cultura no Brasil como tradução da "capacidade do povo brasileiro de se adaptar à novidade e integrá-la no seu cotidiano". ${ }^{2}$

Como veremos, as relações entre o cangaço e a literatura popular de versos, de um modo geral, concentravam-se na sua presença folclórica, mas, aos poucos, o campo mais amplo da cultura popular tornou-se o eixo norteador das reflexões mais recentes, inserido na correlação de forças das relações de poder e de dominação culturais, isto é, como "arena do consentimento e da resistência". ${ }^{3}$ Como apontou Marilena Chaui, essa dupla dimensão de conformismo e resistência possibilita categorizar a cultura popular como "um conjunto disperso de práticas, representações e formas de consciência que possuem lógica própria (o jogo interno do conformismo, do inconformismo e da resistência), distinguindo-se da cultura dominante exatamente por essa lógica de práticas, representações e formas de consciência". ${ }^{4}$

Dentre as possibilidades de análise dessas relações, relacionaremos o fenômeno do cangaço com a emergência da ideia de cultura popular, construída por folcloristas e pesquisadores entre o final do século XIX e primeira metade do século XX, quando há a transformação de determinadas formas e matérias de expressão cultural em ícones de uma dada identidade regional nordestina, "como sendo a verdade e a essência destas manifestações culturais". ${ }^{5}$

A necessária desconstrução dessa ideia essencialista da identidade, de não tomarmos o folclore ou a cultura popular como uma realidade em si, evidencia que esses "conceitos [...] recortam, promovem escolhas, dão visibilida-

\footnotetext{
2 SANTOS, Idelette Muzart-Fonseca dos. Narrativa e imaginário na literatura de cordel brasileira: o cruzamento de linguagens e das modernidades. In: NEMER, Sylvia (org.). Recortes contemporâneos sobre o cordel. Rio de Janeiro: Fundação Casa de Rui Barbosa, 2008, p. 18.

${ }^{3}$ HALL, Stuart. Da diáspora: identidades e mediações culturais. Belo Horizonte: Editora UFMG, 2003, p. 263.

${ }^{4}$ CHAUI, Marilena. Conformismo e resistência: aspectos da cultura popular no Brasil. São Paulo: Brasiliense, 1986, p. 25.

${ }_{5}^{5}$ ALBUQUERQUE JR., Durval Muniz de. A feira de mitos: a fabricação do folclore e da cultura popular (Nordeste 1920-1950). São Paulo: Intermeios, 2013, p. 23.
} 
de e produzem o esquecimento de parte da vasta produção de matérias e formas de expressão feita por agentes das camadas populares". ${ }^{6}$

Por isso, entendemos o campo da cultura como um território de batalha permanente, onde não se obtêm vitórias definitivas, mas há sempre posições estratégicas a serem conquistadas ou perdidas, num jogo de poder que define "as relações estratégicas, as lutas, os afrontamentos, as alianças, as adesões e as subordinações que estão na base da produção desses conceitos e das identidades culturais que eles constituem". ${ }^{7}$

Nesse período de passagem do século XIX para o século XX, as modificações nas formas de percepção e sensibilidades sociais, traduzidas no anseio de mudanças de ordem política, social e cultural, incidiram na busca da identidade nacional, especialmente na trama que envolvia as relações entre as elites culturais e as massas analfabetas. A luta pela instrução básica, desencadeada, sucessivamente, ao longo da Primeira República e defendida por escritores como Olavo Bilac e Coelho Neto, apresentava-se como uma plataforma de uma campanha mais ampla e de propósitos mais profundos, visando, em última instância, à redenção das camadas populares de sua condição de indigência social. Esse "missionarismo cultural" baseava-se na propaganda heroica e solitária de extirpar o analfabetismo e conduzir o Brasil às sendas do "progresso e da civilização". Apesar da diversidade literária da Belle époque brasileira, a tarefa missionária de testemunhar o país conduziu a literatura a um apego à estética instrumental, que se prestava a veiculação de seus ideais sociais e a divulgação profusa de seus projetos de modernização do Brasil, num anseio paternalista, de fundo autoritário, do desejo de exercer tutela por parte dos intelectuais. ${ }^{8}$

É nessa perspectiva que a chamada Geração de 1870 se debruçou sobre a questão de definir o Brasil, a partir de um duplo esforço de identificação: “ao mesmo tempo que absorviam e reelaboravam as matrizes teóricas do pensamento europeu, procuravam, de um lado, encontrar a expressão genuína de uma possível cultura brasileira - o 'verdadeiro Brasil' - e, de outro, apontar os obstáculos que impediam a realização do país enquanto nação". 9

Sob a influência do modelo naturalista e evolucionista de Hippolyte Taine e de Herbert Spencer, pautado das noções de raça e natureza, o sertão se transformou em categoria fundamental para se pensar o Brasil. ${ }^{10}$ Intelectuais como João Capistrano de Abreu e Euclides da Cunha, entre outros, contribuíram para a articulação do sertão/nação na história intelectual no Brasil. Para o primeiro, o sertão foi pensado "enquanto afastamento de Portugal, ruptura com os laços metropolitanos" ${ }^{11}$, deixando para trás o litoral como locus privilegiado da história colonial e transformando o sertão e o traçado dos caminhos

\footnotetext{
${ }^{6}$ Idem, ibidem, p. 177.

${ }^{7}$ Idem, ibidem, p. 178.

${ }^{8}$ Ver SEVCENKO, Nicolau. O fardo do homem culto: literatura e analfabetismo no prelúdio republicano. Almanaque: Cadernos de Literatura e Ensaio, n. 14, São Paulo, 1982.

${ }^{9}$ MOTA, Maria Aparecida Rezende. Sílvio Romero: dilemas e combates no Brasil da virada do século XX. Rio de Janeiro: Editora FGV, 2000, p. 28.

${ }^{10}$ Ver VENTURA, Roberto. Estilo tropical: história cultural e polêmicas literárias no Brasil (1870-1914). São Paulo: Companhia das Letras, 1991, p.18.

11 SOUZA, Candice Vidal e. A pátria geográfica: sertão e litoral no pensamento social brasileiro. Goiânia: Editora UFG, 1997, p. 54.
} 
antigos ligados ao povoamento do interior em centro da narrativa da nação brasileira. ${ }^{12}$ Para o segundo, a Guerra de Canudos trouxe "a questão de como entender o povo pobre do interior e das cidades", colocando-a em um "lugar fundamental no pensamento nacional". ${ }^{13}$

Compartilhando desses preceitos, Sílvio Romero empreendeu, com Estudos sobre a poesia popular no Brasil (1888), a aplicação das teses de J. G. Herder e H. Spencer às manifestações culturais populares, tomando como base o folclore rural. Sob a influência do primeiro, Romero afirmava a existência de uma "uniformidade na cultura, apesar das peculiaridades de cada região do Brasil, acentuadas pela diversidade econômica". Para ele, a existência de uma poesia popular brasileira era a prova desse pertencimento e nos individualizava perante as outras nações. Desse modo, os cantos e contos de origem portuguesa, africana ou indígena se constituíam em uma unidade poética "genuinamente nacional", fruto da mestiçagem como fusão e transformação. ${ }^{14}$

Sílvio Romero dedicou-se a desvendar a "psicologia do homem brasileiro" pelas lentes do folclorismo, mostrando a rica cultura popular brasileira, por meio de uma seleção de materiais populares considerados "autênticos", como poemas, formas musicais, danças, lendas e narrativas. Nesse processo, que vai do início da República até 1920, “cresceu entre os intelectuais a valorização do folclore rural juntamente com a busca (um tanto esquemática) por identificar os "tipos populares brasileiros autênticos'". 15

Em Cantos populares do Brasil, Sílvio Romero registrou, em versão sergipana, as aventuras do mais famoso bandido da Bahia entre 1835 e 1849: Lucas da Feira. Antes de Antônio Silvino e Lampião, esse bandoleiro foi tema do romanceiro popular, principalmente nos famosos ABCs. Na versão utilizada por Romero, temos o registro da traição realizada por um companheiro salteador Casumbá, que o feriu, possibilitando sua prisão e posterior enforcamento. Apesar de Luís da Câmara Cascudo considerar a versão de Silvio Romero deturpada, encontramos nela o processo de diabolização do bandido que repercutirá, posteriormente, na caracterização da figura de Lampião na literatura de folhetos:

\section{Quando na Bahia entrei \\ Vi muita cara faceira; \\ Brancos e pretos gritando: \\ - Lá vem o Lucas da Feira! \\ Quando eu no Rio entrei \\ Caiu-me a cara no chão; \\ A rainha veio dizendo: \\ - Lá vem a cara do cão. ${ }^{16}$}

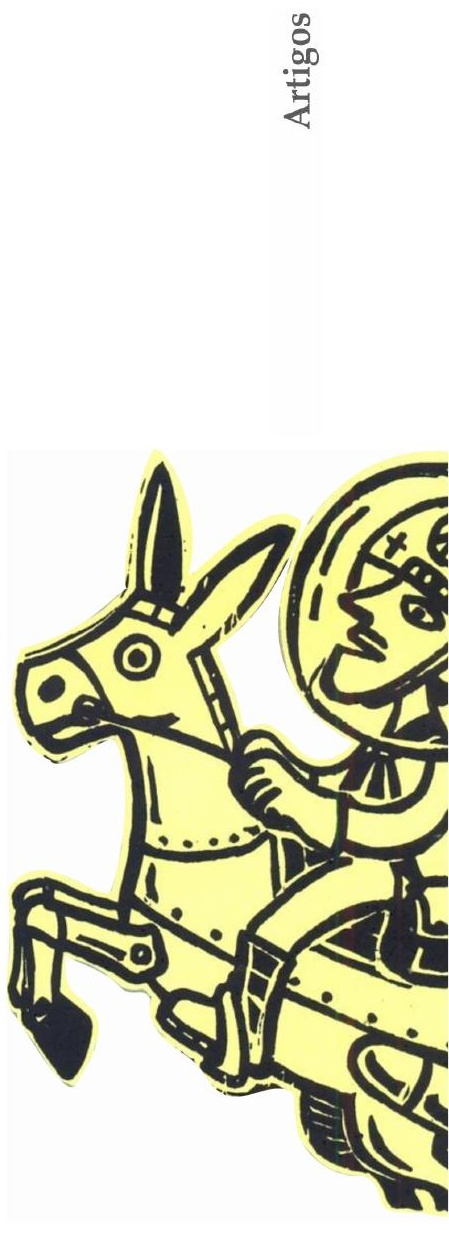

\footnotetext{
12 Ver FALCON, Francisco José Calasans. O Brasil de Capistrano de Abreu: características de sua produção historiográfica. Trajetos: Revista de História UFC, v. 3, n. 5, Fortaleza, 2004 (Dossiê Capistrano de Abreu). 13 WEFFORT, Francisco Correa. As escritas de Deus e as profanas: notas para uma história das ideias no Brasil. Revista Brasileira de Ciências Sociais, v. 20, n. 57, São Paulo, 2005, p. 22.

${ }^{14}$ Ver MOTA, Maria Aparecida Rezende, op. cit., p. 89 e 91.

${ }^{15}$ NAPOLITANO, Marcos. História do Brasil República: da queda da Monarquia ao fim do Estado Novo. São Paulo: Contexto, 2016, p. 61.

16 Apud ROMERO, Silvio. Folclore brasileiro: cantos populares do Brasil. Belo Horizonte-São Paulo: Itatiaia/Edusp, 1985, p. 116.
} 
Na Bahia, a poesia narrativa adquiriu a forma de $A B C$, retratando os fatos cotidianos para serem consumidos em bancas situadas em feiras e mercados das cidades. No caso de Lucas de Feira, sua fixação memorial nos sertões baianos como memória de resistência e rebeldia escrava contribuiu para a construção de uma tradição de heróis negros que teve, entre seus divulgadores, a literatura de Jorge Amado. José Calasans identificou a ambição em seus personagens de serem cantados nos versos de um $\mathrm{ABC}$, como o negro Antônio Balduíno, em Jubiabá. Segundo o pesquisador, esse popularíssimo ABC de Lucas da Feira se constituiu na principal peça folclórica do folclore histórico do recôncavo. ${ }^{17}$

Ainda que as manifestações culturais populares se tornassem tema de alguns dos principais intelectuais da Belle époque tropical, a predominância da cultura letrada encobria a silenciosa cultura das classes subalternas, como é o caso da literatura popular. Mesmo sem "dominar os códigos de escrita e, a meio caminho da oralidade e da música, toda literatura popular, originalmente surgida como folhas volantes, ou folhetos (pliegos sueltos), ou folhas dobradas, foi se transmutando, sobretudo nas regiões Norte e Nordeste, em brochuras chamadas cordéis - anunciadas em pregões e por cantadores em feiras e nas ruas das cidades". 18

O advento do folheto no Brasil no final do século XIX foi um modo eficaz de fixação e preservação das narrativas orais oriundas do período colonial, tornando-se um meio de lazer e literatura dos pobres nas populações rurais e urbanas das cidades nordestinas. Frise-se que os poetas se serviram do noticiário jornalístico para escrever seus versos. Entretanto, “os poemas de época não se confundem com o relato jornalístico dos acontecimentos", pois as notícias eram transmitidas "através de uma outra linguagem". ${ }^{19}$

Os folhetos traziam a realidade imediata e o tema do cangaço adquiriria relevância no imaginário popular brasileiro. ${ }^{20}$ Como apontou Daus, o ciclo de cangaceiros exerceu tamanha influência nos leitores do sertão como nenhum outro ciclo de poesia popular, o que possibilita nos informar "sobre a estrutura psicológica do comportamento dos sertanejos" e "sobre desejos e frustrações da esmagadora maioria da população do Nordeste brasileiro". ${ }^{21}$

A migração de nordestinos para os grandes centros urbanos, especialmente a partir dos anos 1940, trouxe novas modalizações desse suporte da memória produzida pelos folhetos de cordel sobre o cangaço, colocando questões relevantes para o debate entre a tradição e a modernidade na cultura popular no Brasil contemporâneo. Como sabemos, a memória social engloba um vasto repositório de informação em que assenta o viver social, gerada, transmitida e adquirida através da dimensão performativa da existência da socie-

\footnotetext{
17 Cf. CALASANS, José. O folclore histórico do recôncavo da Bahia. Revista de Cultura da Bahia, n. 3, Salvador, jul.-dez. 1971.

18 SALIBA, Elias Thomé. Cultura. In: SCHWARCZ, Lilia M. (coord.). História do Brasil nação: a abertura para o mundo (1889-1930). São Paulo: Objetiva/Fundación MAPFRE, 2012, v. 3, p. 264.

19 TERRA, Ruth Brito Lêmos. Memória de lutas: literatura de folhetos do Nordeste (1893-1930). São Paulo: Global, 1983, p. 72.

20 Ver SANTOS, Olga de Jesus \& VIANNA, Marilena. O negro na literatura de cordel. Rio de Janeiro: Fundação Casa de Rui Barbosa, 1989, p. 14.

${ }^{21}$ DAUS, Donald. O ciclo épico dos cangaceiros na poesia popular do nordeste. Rio de Janeiro: Fundação Casa de Rui Barbosa, 1982, p. 21.
} 
dade. Ao mesmo tempo em que é concretizada ao nível das relações familiares, nos gestos desempenhados no cotidiano, nos hábitos enraizados, a memória social estabelece uma complexa mistura de supressão e de recriação do passado, permitindo, apesar do seu caráter fundamentalmente transformativo, conservar o essencial da recordação sobre o passado. ${ }^{22}$

Nessa perspectiva, a produção de folhetos editados nas primeiras décadas do século XX, constantemente reimpressos, pode ser considerada como "matrizes geradoras de novas narrativas", como uma espécie de "imaginário base", que, aceitas pelo público, "incorporam-se ao 'corpus' inicial". ${ }^{23}$

\section{O cangaço na moderna tradição do cordel}

Para compreendermos uma das possíveis reelaborações desse "imaginário base", em que sobressai a presença do cangaço nos folhetos de cordel, seguiremos a proposta de Peter Burke de dividi-la em dois momentos. Um primeiro momento é marcado pelo mundo do folheto tradicional, tão bem representado pelos poetas Leandro Gomes de Barros (1865-1918), Francisco das Chagas Batista (1882-1930) e João Martins de Atayde (1880-1959), seguido, nas últimas cinco décadas, por um processo de modernização, marcadamente profissional e centralizado em São Paulo pela editora Prelúdio/Luzeiro. ${ }^{24}$

Nos idos de 1893, “o poeta Leandro Gomes de Barros passa a publicar seus poemas em folhetos", iniciando-se "a literatura popular impressa do Nordeste. Outros o seguirão: Francisco das Chagas Batista, que começa a publicar em 1902, e João Martins de Athayde, em 1908". ${ }^{25}$ Apesar de herdarem a literatura oral das cantorias da segunda metade do século XIX, esses poetas populares ganhavam uma autonomia econômica desconhecida dos cantadores, tutelados pelos fazendeiros, tematizando o cotidiano numa diversidade temática, em que sobressaía o cangaço, a política de Salvações no Nordeste, a sedição do Juazeiro, em 1914, e a Primeira Guerra Mundial.

Dentre estes temas, o cangaço transformou-se em um dos principais ciclos épicos da literatura de cordel, a partir da saga de Antônio Silvino, tomado como "tipo de herói-bandido" nos registros versificados de suas façanhas, por vezes, com base nas notícias de jornais ou ainda em "situações fantasiosas e fantásticas em torno dele" ${ }^{26}$

Os romances do ciclo de cangaceiros interessavam muito particularmente aos trovadores e ouvintes nordestinos, como, por exemplo, Antônio Silvino e Lampião, apresentando notável riqueza de invenção ao descrever indivíduos façanhudos tão peculiares aos desafios nordestinos, como a luta de Lampião com o Diabo, mito de Orfeu tão universalizado e que é absolutamente geral na tradição dos cantadores nordestinos. Entretanto, o cordelista não

\footnotetext{
22 Ver CARDIM, Pedro (org.). Cursos da Arrábida: a história: entre memória e invenção. Lisboa: Publicações Europa-América/Comissão Nacional para as Comemorações dos Descobrimentos Portugueses, 1998.

${ }^{23}$ TERRA, Ruth Brito Lêmos, op. cit., p. 71.

${ }^{24}$ Ver BURKE, Peter. Popular poetry in the North-East: the rise and fall of the folhetos. In: TRIBE, Tania Costa (ed.). Heroes and artists: popular art and the Brazilian imagination. Cambridge: Brasil Connects/The Fitzwilliam Museum, 2001.

25 TERRA, Ruth Brito Lêmos, op. cit., p. 17.

${ }^{26}$ PIMENTEL, Altimar de Alencar (seleção e introdução). Francisco das Chagas Batista. São Paulo: Hedra, 2007, p. 42 (Biblioteca de cordel).
} 
abandona a verdade histórica, mas é admirável a destreza com que ele "transporta da verdade pro lendário, fundindo história e liberdade de invenção com uma firmeza excepcional". ${ }^{27}$

A figura do herói popular do cangaceiro era como símbolo da revolta nordestina, representando "a imagem do valente camponês que não se rende" a meio caminho "entre o épico e o picaresco, entre o herói bíblico e o espertalhão valente" ${ }^{28}$ Há uma associação mítica entre os personagens do sertão e do cangaço às figuras de outras literaturas populares, como o ciclo épico de Carlos Magno e os Doze Pares de França, "mantendo traços arquetípicos das comunidades agonísticas - honra, fidalguia e valentia - protestando contra ou celebrando o presente nordestino". ${ }^{29}$

Leandro Gomes de Barros, com A Batalha de Oliveiros com Fierabrás, é um exemplo da utilização "do épico duelo de Oliveiros com o mítico rei de Alexandria, fazendo-o reviver em chave toda nordestina". Também em Rodolfo Coelho Cavalcante, com A chegada de Lampião no céu, vemos Fierabrás se transformando em um enviado do diabo, "que tenta inutilmente reconduzir ao inferno a alma de Lampião protegida pela Virgem". ${ }^{30}$

Gustavo Barroso, em Heróis e bandidos (1917), compara a poesia de Francisco das Chagas Batista com os autores das gestas medievais, afirmando que em "linhas gerais, seu ciclo de canções épicas é tão espontâneo e belo quanto os ciclos épicos dos Francos e Bretões, dos Longobardos e Saxônios, dos Godos e Burgundos". ${ }^{31}$ Desse modo, é estabelecida uma relação "entre os heróis das antigas canções de gesta, celebradas pela tradição, e os novos paladinos do sertão, os cangaceiros, que fazem da lei da honra e do valor na batalha os pressupostos sobre os quais se baseia a lenda criada à sua figura" ${ }^{32}$

Podemos ver essa associação no "Cancioneiro de Lampião", registrado em livro por Nertan Macedo:

\author{
Nos doze pares de França \\ foi buscar inspiração, \\ seu chapéu era igualzinho \\ ao do rei Napoleão, \\ o imperador Carlos Magno \\ houvera de ter paixão, \\ valente como Olivério, \\ brigava como Roldão, \\ dos tempos mais recuados \\ só Osório e Cipião \\ podiam ser comparados \\ ao guerreiro Lampião. ${ }^{33}$
}

\footnotetext{
${ }^{27}$ ANDRADE, Mário de. O Baile das quatro artes. 4. ed. Belo Horizonte: Itatiaia, 2005, p. 99.

${ }_{28}$ PELOSO, Silvano. O canto e a memória: história e utopia no imaginário popular brasileiro. São Paulo: Ática, 1996, p. 105.

${ }^{29}$ CHAUI, Marilena, op. cit., p. 73.

${ }^{30}$ PELOSO, Silvano, op. cit., p. 106 e 107.

${ }^{31}$ BARROSO, Gustavo apud PIMENTEL, Altimar de Alencar, op. cit., p. 32 e 33.

32 PELOSO, Silvano, op. cit., p. 109.

33 Apud MACEDO, Nertan. Capitão Virgulino Ferreira da Silva: Lampião. 2. ed. Rio de Janeiro: O Cruzeiro, 1968, p. 195
} 
Entretanto, há um movimento pendular de ambiguidade nas narrativas literárias entre essa idealização e a diabolização da figura de Lampião. Como um símbolo contraditório, o cangaceiro é associado a múltiplas representações que vão do bandido sanguinário ao bandido social, do justiceiro ao mau-caráter sem escrúpulos, tornando-se, portanto, aberto a várias ressonâncias. $^{34}$

Francisco das Chagas Batista, em O marco de Lampião, coloca o longo enfrentamento de Lampião e o Diabo, que resultou em um pacto: “o diabo protegerá sempre o novo adepto em troca da sua alma e da promessa de obter novas almas entre todas aquelas que Virgulino mandará ao outro mundo durante as suas façanhas". ${ }^{35}$

No clássico O grande debate de Lampião com São Pedro, José Pacheco aborda a vida de Lampião post-mortem como uma sucessão de combates. $\mathrm{O}$ heroísmo, moldado pela sua valentia na terra, ressurge diante de novas situações vividas no além, expondo crenças enraizadas na memória coletiva e na tradição cristã. O lado cômico da cultura popular oferece uma visão de mundo não oficial sobre o além através de outras histórias (fantásticas) que compõem o mito do cangaceiro como valente e guerreiro:

\author{
Lampião the respondeu: \\ - Não venha com seu insulto! \\ Você é um santo bruto - \\ Que ofensa lhe fiz eu? \\ E mesmo o Céu não é seu, \\ Você também é mandado! \\ Portanto, esteja avisado: \\ Se não deixar eu entrar, \\ Nós vamos experimentar \\ Quem é que tem bom guardado! ${ }^{36}$
}

Contrapondo-se ao registro heroico, Leonardo Mota, em No tempo de Lampião (1930), traça um retrato monstruoso e hediondo de Lampião, com base em registros do poeta popular José Cordeiro, afirmando o famigerado bandoleiro obrigava as donzelas a se desnudarem publicamente. No mesmo diapasão é registrado o comportamento infame da polícia por um depoimento de fazendeiro, que o havia hospedado: "Quero mais ante me ver neste oco de mundo, às volta com bandido que com soldado de poliça. [...] Um Tenente no sertão manda mais que um Juiz de Direito. [...] Muito desprepósito, muito abissurdo que se cuida, por aí afora, que foi feito por cangacêro, uma óva: foi, mas foi pela poliça!". ${ }^{37}$

As marcas da tradição oral e da literatura de cordel garantiram a permanência do cangaço na memória social nordestina, com predominância para a figura de Lampião. Por vezes, refletindo os sentimentos ambíguos dos pró-

\footnotetext{
${ }^{34}$ Ver SILVA, Patrícia Sampaio. Le symbole et sés diverses résonances: analyse de l'historiographie du cangaço. Revue Histoire et Société de l'Amerique Latine, n. 4, Paris, mai. 1996.

${ }^{35}$ PELOSO, Silvano, op. cit., p. 114.

${ }_{36}$ PACHECO, José. O grande debate de Lampião com São Pedro. São Paulo: Luzeiro, s./d, p. 8 (Literatura de cordel).

${ }^{37}$ MOTA, Leonardo. No tempo de Lampião. 2. ed. Fortaleza: Imprensa Universitária do Ceará, 1967, p. 49 e 50.
}

:

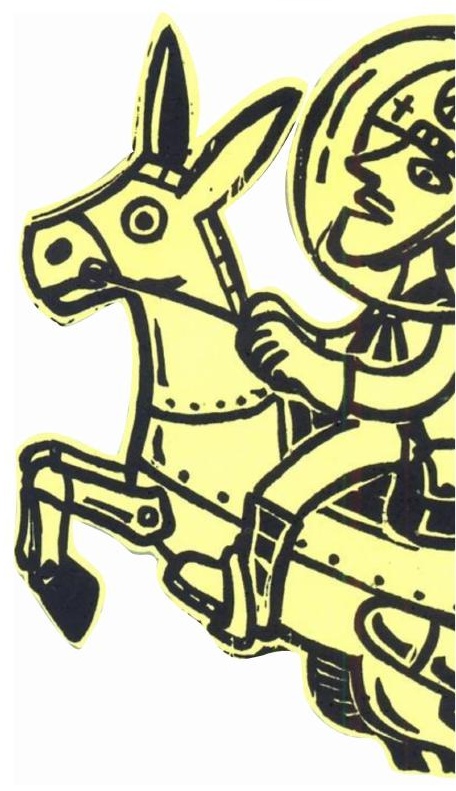


prios camponeses, este bandoleiro é tratado ora como a encarnação do diabo, ora como um herói. Existe um condicionamento da memória camponesa sobre Lampião por parte da tradição oral, trazendo consigo uma dimensão épica nas narrativas. Como vimos, sua imagética pode chegar mesmo a se aproximar dos heróis nobres da Europa medieval, popularizados no princípio da era moderna. A influência dessa memória "não oficial" proveniente da literatura de cordel e da tradição oral vai influenciar um conjunto significativo de obras sobre a história do cangaço, como nos textos de Gustavo Barroso, Frederico Bezerra Maciel e, a reboque da primeira historiadora, Maria Isaura Pereira de Queiroz. ${ }^{38}$

Segundo essa última autora, Lampião "não foi desde o início um mito especificamente ligado às injustiças sociais, em que o bandido aparece como o defensor do povo oprimido. Ele simbolizou, a princípio, o agente do capitalismo dominando os humildes, e isso ao mesmo tempo em que se estava formando a legenda de Robin Hood nacional". 39

Para a socióloga, a construção do mito de Lampião se situa no contexto do nacionalismo emergente dos anos pós-1945, com a tomada de consciência dos problemas sociais, constituindo-se em "símbolo de liberdade contra sujeição; símbolo de renovação a partir das forças vivas contra o enquadramento de coordenadas sociais fossilizantes; símbolo da essência da nacionalidade contra os elementos estrangeiros e externos". ${ }^{40}$ Desse modo, esse mito servia para salientar "características que lhe sejam úteis para reforçar a solidariedade interna das coletividades e para distinguir uma das outras as sociedades globais e, internamente, os grupos que as compõem". ${ }^{41}$

Nessa conjuntura dos anos 1940 e 1960, mudanças gráfico-editoriais ocorreram na literatura de cordel, com a produção da Editora Prelúdio e depois pela Editora Luzeiro, ambas de São Paulo, com a alteração do tamanho clássico dos folhetos de $11,5 \mathrm{~cm}$ por $15,5 \mathrm{~cm}$, destinando-os "ao consumo de massa que lia naquele formato histórias de santos, almanaques, narrativas em prosa voltadas para um grande público". ${ }^{42}$

Esse processo de expansão da literatura de cordel em moldes empresariais por todo o país foi estudado por Joseph Maria Luyten, que identificou críticas por parte de jornalistas, como Edilberto Coutinho, e pesquisadores, como Manuel Diegues Júnior e Raymond Cantel, sobre o "excesso de modernismo e perfeição gráfica" por parte da Editora Prelúdio/Luzeiro. ${ }^{43}$

A uniformização das publicações por parte desta editora, fixando, em média, em 13,5 X 18,5 cm e os volumes em 32 páginas, foi vista por esses pesquisadores e jornalistas como violenta descaracterização dos folhetos. Entretanto, poetas do porte de Rodolfo Coelho Cavalcante e Manoel D'Almeida

\footnotetext{
38 Ver FENTRESS, James e WICKHAM, Chris. Memória social. Lisboa: Teorema, 1994, p. 132.

${ }^{39}$ QUEIROZ, Maria Isaura Pereira de. Notas sociológicas sobre o cangaço. Ciência e Cultura, v. 27, n. 5, Campinas, 1975, p. 495.

${ }^{40}$ Idem, ibidem, p. 509.

${ }^{41}$ Idem, História do cangaço. 4. ed. São Paulo: Global, 1991, p. 68.

42 AYALA, Maria Ignez Novais. ABC, folheto, romance ou verso: a literatura impressa que se quer oral. Graphos, v. 12, n. 2, João Pessoa, 2010, p. 66.

${ }^{43}$ Ver LUYTEN, Joseph Maria. A literatura de cordel em São Paulo: saudosismo e agressividade. São Paulo: Loyola, 1981, p. 111 e 112.
} 
Filho defenderam a excelência da produção editorial desta editora, bem como do eficiente processo de distribuição dos folhetos.

Apesar da boa intenção de pesquisadores e jornalistas em seu zelo pela autenticidade de manifestações populares, percebe-se "uma imposição das elites, das classes dominantes, para uma manutenção do status quo, da pobreza incipiente em que se encontra o artista popular". O aumento da produção de folhetos trouxe prestígio ao autor, com a introdução de ficha biobibliográfica, e uma relação contratual com a editora Prelúdio/Luzeiro, tornando-se modelo para outras editoras da literatura de cordel, como a Tipografia e Livraria Bahiana, de Salvador. ${ }^{44}$

As capas agora se aproximam da ilustração de capas de gibis e de estórias de faroeste, vendidas em bancas de revista, e a produção editorial passava agora pelo "crivo de Manoel d'Almeida Filho, poeta escritor de folhetos, contratado como editor desta coleção, e depois dele por outros editores". Desse modo, o "sistema editorial, antes exclusividade dos prelos nordestinos, ao ser produzido fora da região, começa a se assemelhar, pelos aspectos exteriores, com o das editoras voltadas para o consumo de massa". ${ }^{45}$

Essa aproximação com a cultura de massas foi além da imitação, resultando, por parte da Editora Luzeiro, numa proposta de cordel em quadrinhos que pode ser considerada "como um dos marcos da transferência tecnológica em editoração no Brasil", pois a "passagem da impressão tosca para uma expressão refinada já é um grande passo, mas a mudança semiológica dá ao produto um ar de grande realização tecnológica". ${ }^{46}$

Entretanto, essa experiência foi breve e, não obstante a presença de quadrinistas de renome, como Nico Rosso e Sérgio Lima, “a tentativa de quadrinização da Literatura de Cordel não passou de sofisticada ilustração", limitando a dinamicidade dos quadrinhos com a manutenção de páginas inteiras de poemas sobre o cangaço. ${ }^{47}$

Essa experiência foi depois retomada por Klévisson Viana (2000), que estabeleceu, com o álbum Lampião... Era o cavalo do tempo atrás da besta da vida, vencedor do prêmio HQ MIX de melhor Grafic Novel de 1998, uma fatura mais produtiva, do ponto de vista da linguagem, entre a nova literatura de cordel e a história em quadrinhos. Por meio da editora Tupynanquim, fundada em 1995, seu trabalho se propõe a uma "atualização estética do folheto sem perder sua essência, mantendo-se fiel as suas origens e características originais". ${ }^{48}$

Esse exemplo de utilização do espaço virtual para criar e vender seus folhetos demonstra, de modo cabal, a capacidade de se mover e viver na contemporaneidade, dominando seus instrumentos e modernidade. ${ }^{49}$ Entretanto, dentro do processo de modernização dos folhetos, mantém-se a sextilha como a forma fundamental dos folhetos, coexistindo novos temas ao lado dos tradicionais, como é o caso da sátira Lampião na ONU defendendo o Terceiro Mundo,

\footnotetext{
${ }^{44}$ Idem, ibidem, p. 134 e 135.

${ }^{45}$ AYALA, Maria Ignez Novais, op. cit., p. 66.

${ }^{46}$ LUYTEN, Joseph Maria, op. cit., p. 140 e 141.

${ }^{47}$ Ver Idem, ibidem, p. 142.

${ }^{48}$ Disponível em <https://tupynanquimeditora.blogspot.com/>. Acesso em 17 ago. 2019.

${ }^{49}$ Ver SANTOS, Idelette Muzart-Fonseca dos, op. cit., p. 18.
} 
de Franklin Maxado, mas a maioria dos escritos traz assuntos atuais, principalmente por conta da concorrência dos meios de comunicação de massa, como a televisão.

A proposta de "decodificação" das mensagens midiáticas e sua "transcriação" em versos foi uma das formas utilizadas por Apolônio dos Santos para se manter atualizado e intervir no tempo presente, pelo menos desde os anos 1960. Para ele, o "jornal e o rádio auxiliam o poeta dando-lhe os fatos de que carece. A televisão dá-lhe ideia para estórias novas". ${ }^{50}$

Entretanto, o que interessava ao público leitor do folheto não é descrição dos acontecimentos, mas a narração que é realizada pelo poeta. Segundo Mariane Santos, citando Slater, o "poeta não se atém apenas à descrição do acontecimento, ele realiza em conjunto uma 'reflexão moral'", principalmente por haver certa "incidência de finais justos ou mesmo felizes". ${ }^{51}$

A modernização relacionava-se também às performances dos poetas, que utilizam microfones e registram os folhetos em LPs e cassetes. Muitos poetas passam a viver na grande cidade, como são os casos de Franklin Maxado e Jotabarros que moravam e trabalharam em São Paulo, imprimindo seus cordéis na Rua Augusta. ${ }^{52}$

Se o diálogo entre o cordel e os meios de comunicação de massa foi realizado ao longo do século XX, recentemente o mundo das novas tecnologias, especialmente a internet, tem servido de base para reler acontecimentos pretéritos, numa dialética presente-passado-presente. De modo contraditório, os folhetos sobre o cangaço preservam a tradição dos costumes sertanejos contra a modernidade e, ao mesmo tempo, tentam se adaptar ao mundo cibernético, produzindo textos em que a internet comparece com frequência cada vez maior nessas narrativas, às vezes se aproximando da ficção científica. É o estranhamento com as mudanças culturais no sertão, confrontando valores arcaicos e modernos, em que esses folhetos se afastam da tese euclidiana do suposto isolamento cultural sertanejo, ultrapassada pela diluição entre as fronteiras entre cidade e campo e a marcante presença das novas tecnologias.

Esse estranhamento da figura de Lampião entre signo antimoderno, sinônimo do atraso dos sertões nordestinos, e "cabra moderno" foi representada no folheto de Marcelo Soares, filho do poeta-repórter José Soares (19141981). Em 2002, colocando-se na condição de "micreiro famoso", o cordelista estabelece um diálogo com o cangaceiro Lampião por meio do computador, que não nega sua maldade, mas reclamava que, nas profundezas do inferno, não existia computador e "eu também sou moderno", pretendendo "informatizar/Meu bando de cangaceiros". ${ }^{53}$

Se conseguir, do inferno "o mundo vai mudar", restaurando-se o modo antigo de viver no sertão: "Moça terá que ser virgem/ Para poder casar" e para o inferno virão os "políticos corruptos E ladrões da consciência", "Os

\footnotetext{
50 SANTOS, Apolônio dos apud SANTOS, Mariane Nascimento dos. Política dos tubarões e sociedade da carestia: a redemocratização do Brasil nos folhetos de cordéis de Apolônio Alves dos Santos (1974-1992). Dissertação (Mestrado em História) - UFS, São Cristóvão, 2016, p. 74.

51 Idem, ibidem, p. 60 e 59.

52 Ver BURKE, Peter, op. cit., p. 47 e 48.

53 SOARES, Marcelo. A volta do cangaceiro Lampião via internet. Timbaúba: Folhetaria Cordel, 2002, p. 5 (Literatura de cordel).
} 
pederastas devassos" e a "Mulher que trai o marido" ${ }^{54}$ Esse viés conservador do folheto se manifesta nas estrofes finais: "Oh! meu Anjo Cangaceiro/ Abençoai o Sertão/ Rei é o Nosso Senhor/ E o tal computador/ Só serve de distração". 55

Em outra chave de leitura do cangaço na pós-modernidade, Klévisson Viana, em $O$ Cangaceiro do futuro e o jumento espacial, propôs um novo gênero "baseado/Na ficção científica/E no cordel bem rimado". Apesar de sua proposta ser escrever uma "história futurista" ambientada no ano de 2100, o folheto mantém a denúncia contra os políticos tradicionais do Ceará em sua estratégia de dominação contra a população mais pobre, agora utilizando-se do "voto eletrônico/ Que manipula a eleição":

\section{O coronel Galê Site \\ Maluco sem consciência \\ Clonado diversas vezes \\ Se aproveita da ciência \\ Para ficar no poder \\ Esnobando a Providência ${ }^{56}$}

O espaço sideral foi utilizado também por outro importante cordelista, Antônio Carlos de Oliveira Barreto, que estabeleceu contato com Maria Bonita, via e-mail, para compor um cordel "responsável e fiel". Como estava à frente do seu tempo, ela soube conviver entre os homens de Lampião, sem se curvar ao ambiente machista. Para o cordelista, Maria Bonita parecia "Sherazade", "Ajudando Lampião/ Na hora de decidir/ Com atitudes sensatas/ Visando um novo porvir". 57

Essa leitura de coragem e sensibilidade femininas num mundo dominado por homens a faz adotar uma postura revolucionária, segundo o folheto:

Voz altiva no cangaço

Ao lado de Lampião

Maria Déa passou

A brilhar na sua missão

Mostrando que a mulher

É muito mais que emoção

Sem perder, nem macular

Sua feminilidade

Maria Bonita foi

Símbolo da liberdade

Musa revolucionária

Pra seu tempo e sua idade 58

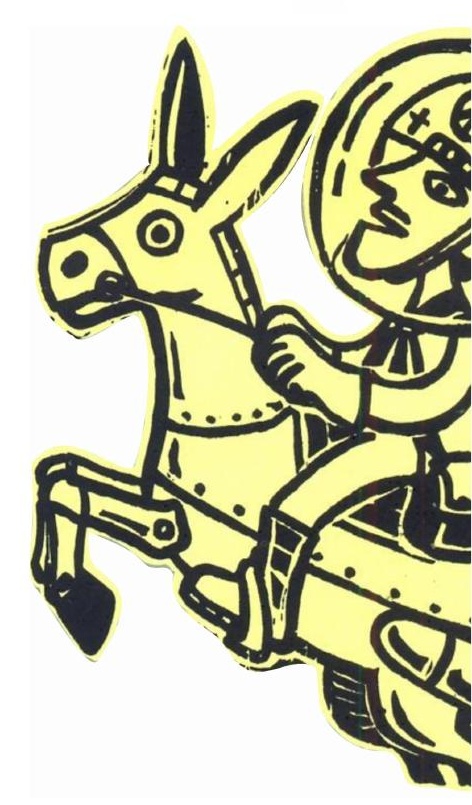

\footnotetext{
${ }^{54}$ Idem, ibidem, p. 4.

${ }^{55}$ SOARES, Marcelo, op. cit., p. 8.

${ }^{56}$ VIANNA, Klévisson. O cangaceiro do futuro e o jumento espacial. Fortaleza: Tupynanquim, 2008, p. 2.

${ }^{57}$ BARRETO, Antônio Carlos de Oliveira. Maria Bonita: a musa de Lampião. Salvador: e./ed., 2010, p. 1 e 6

(Literatura de cordel).

${ }^{58}$ Idem, ibidem, p. 5.
} 
No acróstico definidor da autoria, Barreto estabelece certo romantismo revolucionário na interpretação do cangaço:

\author{
Bravura pelos sertões \\ Altivez, encantamento \\ Rebeldia, dor, mistério \\ Romantismo, alumbramento \\ Entusiasmo, ternura... \\ Tiveste amor e doçura: \\ Oh Maria, o teu alento ${ }^{59}$
}

Dentro da mudança na estrutura do sentimento na pós-modernidade, a emergência discursiva do feminino no cangaço trazia contradições na representação de uma mulher forte e bela, como Maria Bonita, num cenário marcadamente patriarcal. Como apontou Daniel Lins, os "poetas a descreveram bela como uma princesa, forte como uma guerreira, inteligente e misteriosa como uma deusa do Olimpo sertanejo! Com seus olhos 'azuis cristalinos', ela seduzia e hipnotizava Deus e o diabo!"60, como no texto clássico de Antônio Teodoro dos Santos, em Lampião: o rei do cangaço, que a definiu por sua beleza e a transformação das regras do cangaço pela força poderosa do amor, cujas mulheres eram consideradas como guerreiras e não apenas companheiras:

\title{
Alguém que não conheceu \\ A mulher de Lampião \\ Seu nome diz a beleza \\ E a proeza o coração \\ Lutava contra a polícia \\ Tinha coragem e perícia \\ Destreza no mosquetão ${ }^{61}$
}

Em mulheres no cangaço, Varneci Nascimento e Nando Poeta denunciam o machismo em sua narrativa, construindo uma imagem de valentia e coragem para as mulheres que "Sem temer a desventura/ Foi habitar o cangaço". Tentando associar às mudanças na estrutura do sentimento, de quebra de paradigma do machismo, esse texto sugere que o "feminismo" superou a imagem da "fase selvagem" do cangaço, quebrando "os paradigmas/ Na caatinga nordestina". ${ }^{62}$

Além da famosa rainha do cangaço, esses cordelistas recuperam a figura de Anésia Cauaçu, "Que clamava por justiça/ Usando da coragem/ Combateu a injustiça/ Na Chapada Diamantina/ Sua braveza a atiça". ${ }^{63}$ Assim, essa narrativa desempenha papel relevante na memória das mulheres do cangaço, elencando os nomes das dezenas que participaram do movimento bandoleiro, "amansando" a brutalidade dos cangaceiros:

\footnotetext{
${ }^{59}$ Idem, ibidem, p. 8.

${ }^{60}$ LINS, Daniel. Lampião: o homem que amava as mulheres. São Paulo: Annablume, 1997, p. 61.

${ }^{61}$ SANTOS, Antônio Teodoro dos. Lampião: o rei do cangaço. São Paulo: Luzeiro, 1959, p. 23 (Literatura de cordel).

${ }^{62}$ NASCIMENTO, Varneci e POETA, Nando. As mulheres no cangaço. São Paulo: Luzeiro, 2014, p. 13 (Literatura de cordel).

${ }^{63}$ Idem, ibidem, p. 16.
} 
Delicadamente iam

Tornando o homem mais manso.

Esqueciam as velhas práticas,

Um considerável avanço.

Nas relações entre gênero

Aboliram todo o ranço. ${ }^{64}$

Nesse mesmo diapasão, também o poeta Zé Antônio versejou Maria Bonita como "domadora de feras":

\author{
Maria Bonita \\ Fez sua revolução \\ Domando a grande fera \\ O famoso Lampião \\ Enfrentando embaraço \\ Foi rainha do cangaço \\ Nas caatingas do sertão $0^{65}$
}

De um modo geral, os poetas populares incluíram as mulheres à gesta do cangaço a partir do ciclo das histórias de amor, pois se Lampião é capaz de amar, isso resultou em um processo de humanização do famoso bandoleiro. Assim, essas narrativas literárias têm realizado um reaproveitamento inovador da tradição oral e do imaginário nordestino, proporcionando uma visão amainada do cangaceiro, não o colocando como bandido muito menos como herói, mas como seres demasiado humanos. ${ }^{66}$

\title{
O cangaço revisto na perfomatividade do cordel
}

As relações entre o cangaço e a cultura popular foram aqui pensadas no contexto do vasto repositório de informação em que assenta o viver social, gerada, transmitida e adquirida através da dimensão performativa da sociedade, marcada pelo "cruzamento das linguagens e das modernidades", como apontado por Idelette Muzart-Fonseca dos Santos. Os folhetos acompanharam as transformações sociais, econômicas e culturais ocorridas na sociedade brasileira nos séculos XX e XXI, demonstrando enorme "capacidade de renovação e permanente absorção de narrativas, de linguagens, de imaginário" ${ }^{67}$ Portanto, sem negligenciar o "imaginário-base" da produção de folhetos clássicos, com seus elementos tradicionais, editados nas primeiras décadas do século $X^{66}$, é forçoso "reconhecer a total modernidade dessa abordagem do real, dessa integração de formas e linguagens oriundas dos mais diversos horizontes, bem como do aproveitamento das novas técnicas de comunicação" desenvolvidas nos séculos XX e XXI, da imprensa escrita à comunicação virtual e internet. ${ }^{69}$

\footnotetext{
${ }^{64}$ Idem, ibidem, p. 26.

65 ANTÔNIO, Zé. Como Maria Bonita desafiou Lampião. Aracaju: Datagraph, 2018, p. 5 (Literatura de cordel).

66 Ver MELO, Andréa Patrícia Santos. A rainha do cangaço nos folhetos de cordel. Ponta de Lança: Revista Eletrônica de História, Memória \& Cultura, v. 3, n. 5, São Cristóvão, out. 2009-abr. 2010, p. 74.

${ }^{67}$ SANTOS, Idelette Muzart-Fonseca dos, op. cit., p. 15 e 24.

68 Ver TERRA, Ruth Brito Lêmos, op. cit., p. 71.

${ }^{69}$ Ver SANTOS, Idelette Muzart-Fonseca dos, op. cit., p. 24.
} 
A diluição entre as fronteiras entre cidade e campo e a marcante presença das novas tecnologias, com a consequente compressão do espaçotempo, típica da modernidade tardia ou pós-modernidade, fizeram com que a leitura dos folhetos sobre o cangaço estabelecesse recriações das histórias tradicionais ou mesmo releituras para se aproximar do leitor contemporâneo. Nessa perspectiva, numa dialética presente-passado-presente, esses folhetos buscam preservar os costumes tradicionais sertanejos e, ao mesmo tempo, adaptam-se ao universo da internet, transformado em um personagem partícipe das narrativas.

Os textos dos folhetos também trazem revisões sobre as permanências culturais do arcaísmo patriarcal, pois, apesar das transformações culturais que tentam superá-lo, a violência como código de honra ainda se mantém vivo neste sertão pós-moderno. Na reconstrução da memória regional, esses poetas transportavam "verdade pro lendário, fundindo história e liberdade de invenção com uma firmeza excepcional"..$^{70}$ Influenciados pelos "novos tempos", o papel das mulheres assume protagonismo nas narrativas dos folhetos, por vezes pecando por certo anacronismo ao colocar as cangaceiras como "feministas". Essa liberdade criativa contribuiu para o processo de humanização de Lampião, com a entrada de mulheres nos bandos, estabelecendo um entrecruzamento dos discursos histórico e ficcional, entre a história factual e a produção literária. ${ }^{71}$

Os folhetos fazem parte dessa revisão histórica do cangaço empreendida por outras artes, como, por exemplo, o romance Os desvalidos, de Francisco J. C. Dantas (1993), ou a peça teatral de Marcos Barbosa, intitulada Auto de Angicos (2003), numa reinterpretação cultural do cangaço, em que se configura numa outra proposta de produção da memória social do fenômeno, que se afastados determinismos climáticos, raciais e culturais que teimam em permanecer em parte da historiografia do tema. Afinal, cangaceiros e cangaceiras eram seres demasiadamente humanos e condicionados pela história dos sertões brasileiros, marcada pela resistência rebelde, mas também pelo conformismo.

Artigo recebido em 7 de abril de 2020. Aprovado em 17 de maio de 2020.

\footnotetext{
${ }^{70}$ ANDRADE, Mário de, op. cit., p. 99.

${ }^{71}$ Ver CAVIGNAC, Julie. A literatura de cordel no Nordeste do Brasil: da história escrita ao relato oral. Natal: Editora da UFRN, 2006, p. 164.
} 